\title{
CDISC SDTM Contact Case Investigation Contact Type Terminology
}

National Cancer Institute

\section{Source}

National Cancer Institute. CDISC SDTM Contact Case Investigation Contact Type

Terminology. NCI Thesaurus. Code C102575.

Terminology associated with the contact case investigation contact type codelist of the Clinical Data Interchange Standards Consortium (CDISC) Study Data Tabulation Model (SDTM). 